\title{
Neutron Irradiation of Electronic Materials at HANARO
}

\author{
Kee-Nam Choo*, Man-Soon Cho, Byung-Hyuk Jun, Chan-Joong Kim, Sang-Jun Park \\ Department of Research Reactor Utilization, Korea Atomic Energy Research Institute, Daejeon, South Korea \\ Email: ${ }^{*}$ knchoo@kaeri.re.kr
}

Received 26 May 2014

\begin{abstract}
HANARO, a 30 MW open-pool type multipurpose research reactor, has been operated as a platform for nuclear researches in Korea, and irradiation facilities have been mainly utilized for various nuclear material irradiation tests requested by users. Although most irradiation tests have been related to national $R \& D$ relevant to nuclear power, demand for neutron irradiation of electro-magnetic materials is increasing rapidly at HANARO. Another research reactor, which is named the KIJANG research reactor (KJRR), is under construction in Korea. KJRR is dedicated to increasing the national radio-isotopes supply capacity and to the irradiation facilities including Neutron Transmutation Doping (NTD) facilities for power semiconductor production in a large scale and fast neutron irradiation (FNI) facility for fast neutron irradiation. The NTD and FNI facilities in the KJRR reactor can be effectively utilized on the study of separated effect of thermal and fast neutron irradiations on the properties of electro-magnetic materials. HANARO will also specialize more on irradiation research, including neutron irradiation of electronic materials. The research status and possibility of new electro-magnetic materials using neutron irradiation at HANARO are surveyed to ascertain the utilization of neutron irradiation technology in electro-magnetic material researches.
\end{abstract}

\section{Keywords}

HANARO, Neutron, Irradiation, Electro-Magnetic Material

\section{Introduction}

The High Flux Advanced Neutron Application Reactor (HANARO) has been operating as a platform for basic nuclear research in Korea, and the functions of its systems have been improved continuously since its first criticality in February 1995. It is now being successfully utilized in such areas as fuel and material irradiation tests and neutron transmutation doping to meet industrial, academic, and research demands. To support the national research and development programs on nuclear reactors and nuclear fuel cycle technology in Korea, rabbit and capsule irradiation facilities have been developed and actively utilized for the irradiation tests requested by numerous users [1]. Continuing efforts to improve the capabilities and instrumentation of the facilities have been in progress at KAERI [2] [3]. The irradiation facilities have been mostly utilized for the KAERI research projects

\footnotetext{
${ }^{*}$ Corresponding author.
} 
related to the National Nuclear R \& D Projects relevant to a commercial nuclear power reactor such as the ageing management and safety evaluation of the components. However, some irradiation tests of electro-magnetic materials were performed for scientific research of universities and the demand for neutron irradiation of electro-magnetic materials is increasing rapidly at HANARO. Another research reactor that will specialize in radioisotope production and the demonstration of reactor design is under construction in Korea. Therefore, HANARO will specialize more on irradiation research. Based on its accumulated irradiation experience, HANARO has recently started new support of R \& D relevant to the irradiation of electro-magnetic materials.

In this paper, not only the status of HANARO irradiation facilities but also the utilization of the facilities and the possibility of new electro-magnetic materials using neutron irradiation at HANARO are surveyed to ascertain the utilization of neutron irradiation technology in electro-magnetic material researches.

\section{HANARO and Utilization for Nuclear Technology}

\subsection{HANARO and Irradiation Facilities}

The High Flux Advanced Neutron Application Reactor (HANARO) is an open pool type multipurpose research reactor with $30 \mathrm{MW}$ thermal power located at the Korea Atomic Energy Research Institute (KAERI) in Korea. In an effort to boost the nation's research capability, HANARO was conceived and constructed in the 1980s using domestic reactor technology from KAERI [4]. As a platform for nuclear basic researches in Korea, HANARO has been operated, and the functions of its systems have been improved continuously since its first criticality in February 1995; and it is now being successfully utilized in such areas as fuel and material irradiation tests, neutron beam research, radioisotopes production, neutron activation analysis, and neutron transmutation doping, etc. to meet the industrial, academic, and research demands. To support the national research and development programs on nuclear reactors and nuclear fuel cycle technology in Korea, various neutron irradiation facilities such as the rabbit (small non-instrumented capsule) irradiation facilities, the capsule irradiation facilities, and the fuel test loop facilities have been developed as shown in Figure 1 [2] [3].

The rabbit was originally designed for isotope production, but it can be used for the irradiation test of fuels and materials. Figure 1 shows the typical rabbit (20 mm in diameter and $30 \mathrm{~mm}$ in length for specimen). It is very useful for numerous irradiation tests of small specimens at a low temperature, below $200^{\circ} \mathrm{C}$, and neutron flux conditions.

The instrumented and non-instrumented capsules have been developed at HANARO for new alloy and fuel developments and the lifetime estimation of nuclear power plants (NPPs). For the development of an instrumented capsule system, the capsule related systems such as a supporting, connecting and controlling system were also developed. After locking the capsule in a test hole, the instrumented capsule is fixed by a chimney bracket and robotic arm supporting systems. The capsule temperature control system consists of three subsystems: a vacuum control system, a multi-stage heater control system and a man-machine interface system. After an irradiation test, the main body of the instrumented capsule is cut off at the bottom of the protection tube with the cutting system, and it is transported to the Irradiated Materials Examination Facility (IMEF) using a HANARO fuel cask.
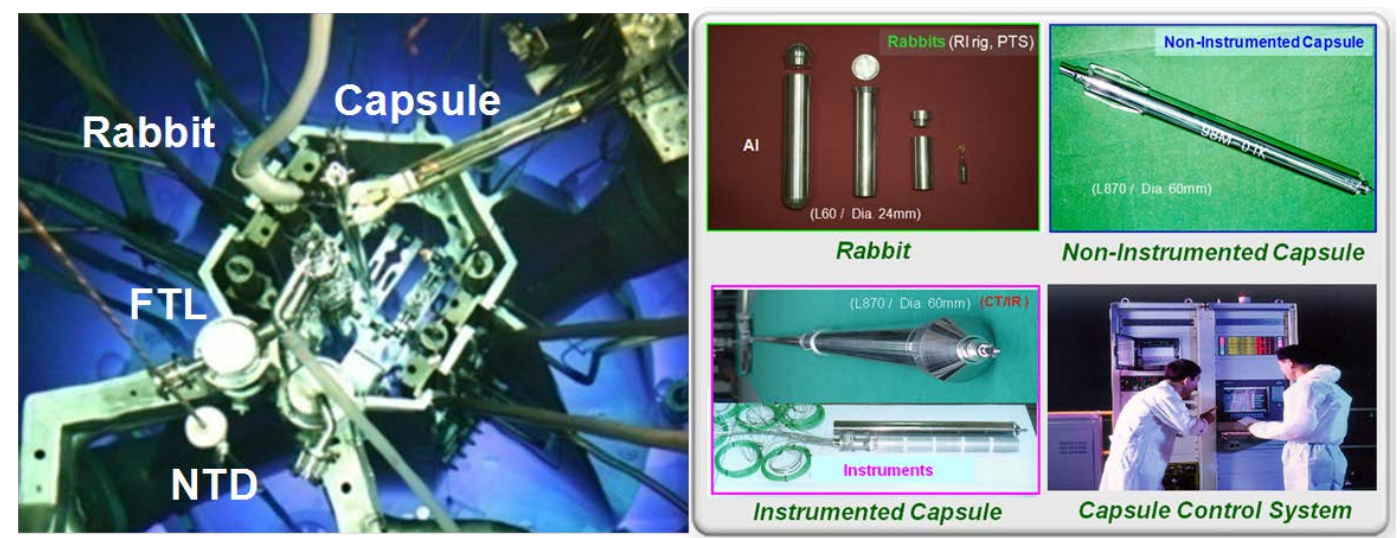

Figure 1. Photograph of the HANARO core and irradiation facilities. 
The FTL is a facility that can conduct fuel and material irradiation tests at HANARO. It is composed of an inpile test section (IPS) and an out-of-pile system (OPS). The IPS in the IR1 irradiation hole can accommodate up to three pins of PWR or CANDU type fuels and has instruments such as a thermocouple, LVDT, and SPND to measure the fuel's performance during a test. The FTL simulates commercial NPP operating conditions such as its pressure, temperature, flow, and neutron flux to conduct irradiation tests. The application fields of the FTL are nuclear fuel and material irradiation tests at the operating conditions of a commercial power plant, fuel burn up and mechanical integrity verification tests, irradiation data generation for a performance analysis model (PWR fuel, CANDU fuel and metallic fuel), technical improvement of a design and fabrication process for advanced fuel development, fuel rod irradiation testing for performance verification and more. The typical design pressure and temperature of the in-pile section of the FTL is $17.5 \mathrm{MPa}$ and $350^{\circ} \mathrm{C}$, respectively. The commissioning of the FTL was performed from April 2007 to September 2009. At present, a cold test is being performed for long-term utilization. The FTL will be used for the irradiation tests of advanced fuels after completion of the commissioning.

HANARO has two irradiation holes for neutron transmutation doping (NTD) to manufacture high-quality ntype semiconductors. A semiconductor doped with neutrons has a much better dopant distribution compared to others made by conventional chemical doping methods, and is especially required for the effective use of high-power operating devices such as insulated gate bipolar transistors (IGBTs), integrated gate commutated thyristors (IGCTs), and gate turn off thyristors (GTOs). The demand for NTD silicon is increasing rapidly with the increase of wind, solar, and fuel cell energy systems; hybrid cars and hydrogen fuel cell engines; and devices to reduce electricity loss. A commercial NTD service for 5, 6 and 8 inch silicon ingots is being performed at NTD1 and NTD2, where the world's best quality products make up about $15 \%$ of the world market share as of 2012. New NTD facilities for a larger silicon ingot such as a 10 or 12 inch ingot are being planned in the new research reactor.

There are two facilities used for performing a post-irradiation examination (PIE) at KAERI. These are the Irradiated Material Examination Facility (IMEF) and the Post-Irradiation Examination Facility (PIEF). Detailed information about these facilities is available on the KAERI home page (http://www.kaeri.re.kr).

\subsection{Utilization of HANARO for Nuclear Technology}

As a platform for nuclear researches in Korea, the irradiation facilities of HANARO have been actively utilized for various nuclear fuel and material irradiation tests requested by users from research institutes, universities, and industries. Since 1995, 12,000 specimens from research institutes, nuclear industry companies and universities have been irradiated at HANARO for 123,000 cumulative hours using the developed capsule and rabbit irradiation systems. One of the major irradiation fields is the support of national research and development program relevant to the commercial nuclear power reactor such as ageing management and the safety evaluation of its components. Another field is the progress of science and technologies (fundamental research, future nuclear systems). Figure 2 shows a typical contribution of neutron irradiation at HANARO for the National Nuclear R \& D Programs. Based on its accumulated experience and the sophisticated requirements of users, HANARO

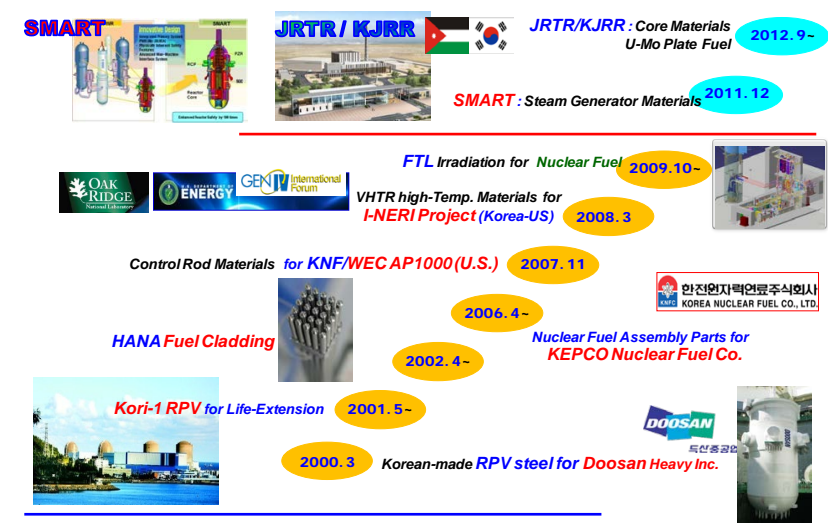

Figure 2. Contribution of neutron irradiation at HANARO for the national nuclear R \& D programs. 
has recently started a new support of R \& D relevant to new nuclear systems including the System-integrated Modular Advanced Reactor (SMART) and future nuclear systems of the very high temperature reactor system (VHTR) and sodium cooled fast reactor system (SFR). To effectively support R \& D relevant to new nuclear systems, the development of advanced irradiation technologies is being actively developed at HANARO.

\section{Irradiation of Electro-Magnetic Materials at HANARO}

\subsection{Irradiation Tests of Electro-Magnetic Materials}

As a national platform for basic and nuclear research, HANARO irradiation facilities have been actively used for irradiation tests of basic research requested by users from research institutes and universities. The irradiation tests requested from users, as shown in Table 1, have been sponsored by the National Project for Active Utilization of HANARO since 2000. The project has a call for research proposals every year. Proposals submitted

Table 1. Neutron irradiation tests of electro-magnetic materials at HANARO.

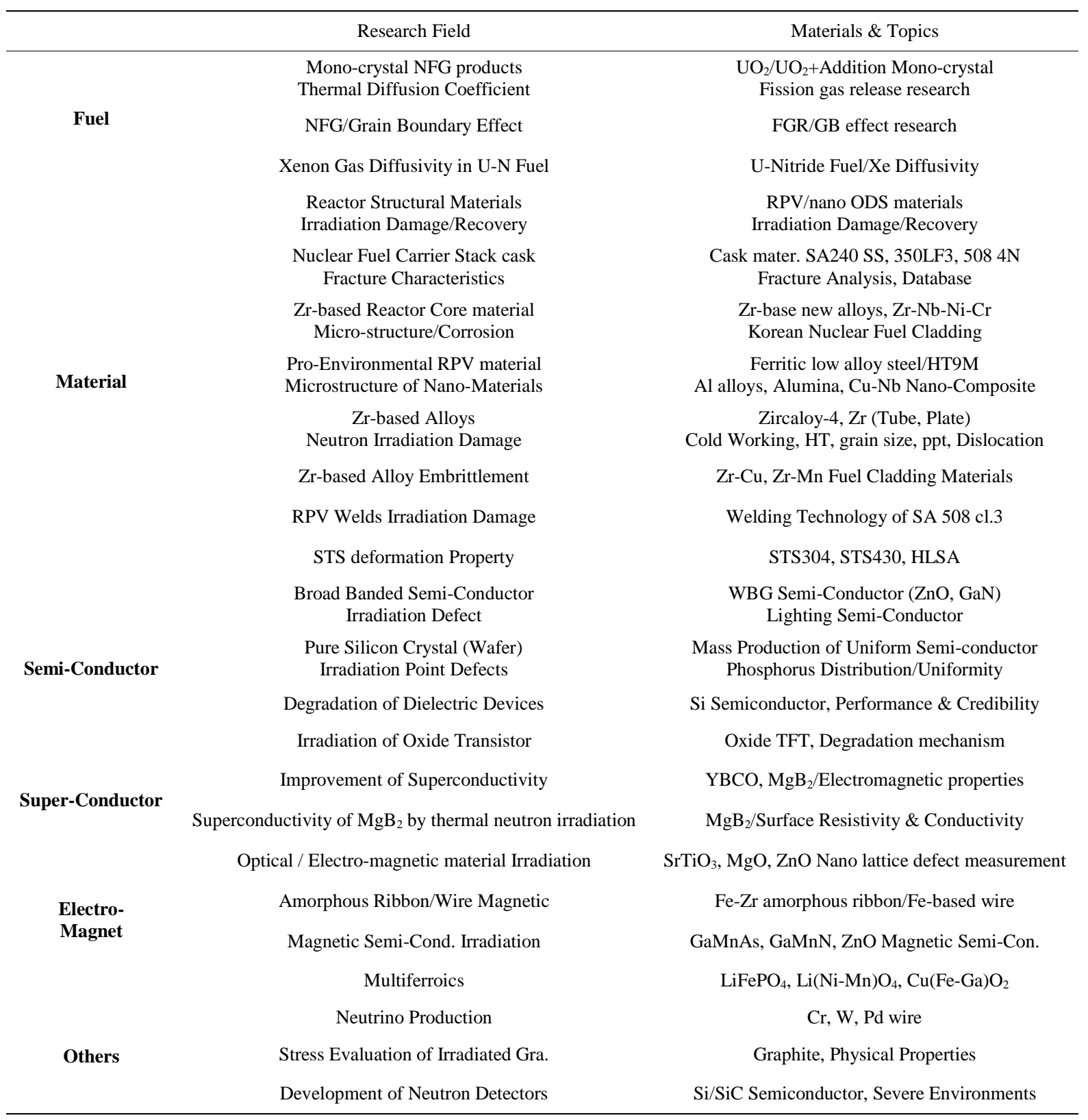


through the homepage (http://www.nrf.re.kr) of the National Research Foundation of Korea (NRF) are competitively selected on the basis of an independent peer review that utilizes expert reviews from universities, national laboratories, and industry.

Various specimens such as nuclear fuels and materials, and new functional materials including conductors and optical/electrical materials have been irradiated using capsule and rabbit systems. The electro-magnetic and optical properties of the materials are closely dependent on the size and density of their internal defects, and neutron irradiation is a very effective method to produce micro-defects in these materials. Therefore, neutron technology can be applied effectively toward the development of new materials. Recently, several efforts have been made at HANARO to evaluate the effect of neutron irradiation on the physical properties of various functional materials [5]-[8].

\subsection{Additional Works near Future}

As neutron irradiation provides 1) Preservation of stoichiometric composition and average number of electrons pre an atom; 2) Opportunity of preservation of macro- and micro-homogeneity of samples; 3) Opportunity of making of defects of various sorts with smooth changing of their concentration. These opportunities of neutron irradiation are unattainable by using any other traditional technological methods. Therefore, the study of a response of a crystal to irradiation influence allows observing unique information about electron states, magnetic interaction and cetera.

The electrical and magnetic properties of electronic materials are extremely dependent upon disorder in lattice structure. Neutron irradiation of these materials greatly increases this disorder through the creation of various defects. Thermal neutron damage is thought to consist of point defects such as divacancies, di-interstitials, and vacancy-impurity clusters. Fast neutron damage consists of extended defect clusters which may contain as many as 1000 defects [9].

Although several impressive effects of neutron irradiation on the properties of electronic materials were reported at HANARO [5]-[8], it was difficult to interpret clearly their behaviors due to the broad energy spectrum of the neutron as shown in Figure 3. The undesirable effects due to thermal and fast neutrons should be reduced to separate each neutron's effect on the properties of the sample. Following the experience with HANARO, KIJANG research reactor (KJRR) is now being constructed by KAERI, dedicated to increasing the national radio-isotopes supply capacity including the self-sufficiency of Mo-99. And the KJRR is also expected to have the capability to provide the neutron irradiation service for power semiconductor production in a large scale. This service includes not only NTD facility for ingot irradiation, but also fast neutron irradiation (FNI) facility for wafer irradiation. Fast neutron irradiation for wafer is a promising technology for efficiency gain and life extension of the power semiconductor. The FNI facility can be effectively utilized on the study of separated effect of fast neutron irradiation on the properties of electro-magnetic materials. The foundation for the research of materials using neutron irradiation has a great possibility in the field of original information of electro-magnetic materials.
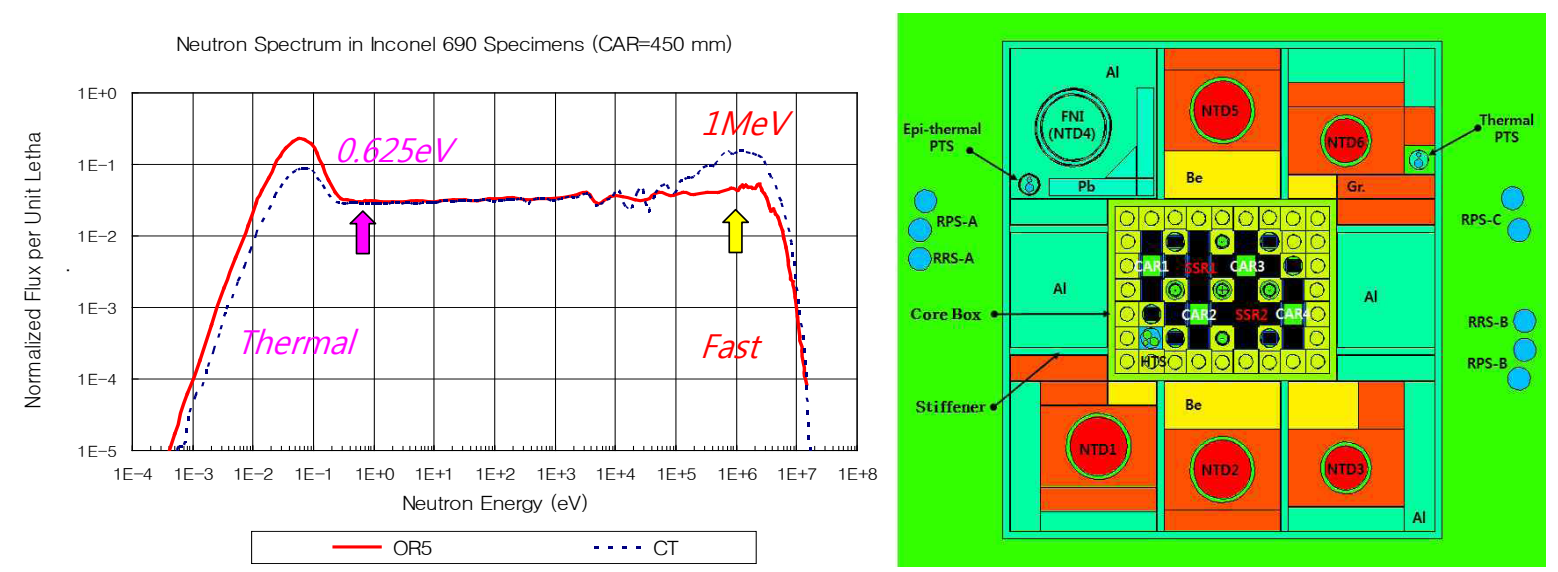

Figure 3. Neutron energy spectrum at HANARO and plan view of the KJRR core. 


\section{Conclusion}

HANARO irradiation facilities have been mainly utilized for various nuclear material irradiation tests requested by users. Although most irradiation tests have been related to national R \& D relevant to nuclear power, the demand for neutron irradiation of electro-magnetic materials is increasing rapidly at HANARO. Following the experience with HANARO, KIJANG research reactor (KJRR) is now being constructed by KAERI, dedicated to increasing the national radio-isotopes supply capacity and to the irradiation facilities including NTD facilities for power semiconductor production in a large scale and FNI facility for fast neutron irradiation by shielding thermal neutron. The NTD and FNI facilities in the KJRR reactor can be effectively utilized on the study of separated effect of thermal and fast neutron irradiations on the properties of electro-magnetic materials. The foundation for the research of materials using neutron irradiation seems to have a great possibility in the field of research of electro-magnetic materials.

\section{Acknowledgements}

This work was supported by the National Research Foundation of Korea (NRF) grant funded by the Korea government (MISP) (NRF-2013M2A8A1035822).

\section{References}

[1] Choo, K.N., Cho, M.S., Kim, B.G., Kang, Y.H. and Kim, Y.K. (2011) Material Irradiation at HANARO, Korea. Research Reactor Application for Materials under High Neutron Fluence, IAEA-TECDOC-1659, IAEA.

[2] Kim, B.G., Sohn, J.M. and Choo, K.N. (2010) Development Status of Irradiation Devices and Instrumentation for Material and Nuclear Fuel Irradiation Tests in HANARO. Nuclear Engineering and Technology, 42, 203-210. http://dx.doi.org/10.5516/NET.2010.42.2.203

[3] Choo, K.N., Kim, B.G., Cho, M.S., Kim, Y.K. and Ha, J.J. (2010) Measurement and Evaluation of the Irradiation Test Parameters for a Specimen in a HANARO Material Irradiation Capsule. IEEE Transactions on Nuclear Science, 57, 2642-2646. http://dx.doi.org/10.1109/TNS.2010.2059044

[4] Choi, C.O., Kim, H.R., Lee, K.H., Lee, C.S. and Sohn, J.M. (2002) Present Situations and Perspective on the Advanced Utilization of HANARO. Physica B, 311, 34-39. http://dx.doi.org/10.1016/S0921-4526(01)01052-3

[5] Kim, Y.S., Phan, M.H., Yu, S.C., Kim, K.S., Lee, H.B., Kim, B.G. and Kang, Y.H. (2003) Annealing and NeutronIrradiation Effects on the Permeability of $\mathrm{Fe}_{86} \mathrm{Zr}_{7} \mathrm{~B}_{6} \mathrm{Cu}_{1}$. Physica B, 327, 311-314. http://dx.doi.org/10.1016/S0921-4526(02)01776-3

[6] Cho, H.D. and Kang, S.K. (2003) Method for Doping GaN Substrates and the Resulting Doped GAN Substrate. US Patent No. 2003/0134493 A1.

[7] Choo, K.N., Cho, M.S., Lee, C.Y., Yang, S.W., Shin, Y.T., Park, S.J., Kang, Y.H., Park, S.J. and Lim, I.C. (2013) Improvement Plan of Irradiation Technology Using Capsule for Next Five Years at HANARO. 6th International Symposium on Material Testing Reactors, Bariloche, 28-31 October 2013.

[8] Kim, C.J., Yi, J. H., Jun, B.H., You, B.Y., Park, H.S.D. and Choo, K.N. (2014) Effects of Neutron Irradiation on Superconducting Critical Temperatures of in Situ Processed $\mathrm{MgB}_{2}$ Superconductors. Progress in Superconductivity and Cryogenics, 16, 9-13. http://dx.doi.org/10.9714/psac.2014.16.1.009

[9] Cleland, J., et al. (1978) Polycrystalline Silicon Semiconductor Material by Nuclear Transmutation Doping. US Patent No. 4129463. 